\title{
Lessons Learned Through Leadership
}

John L. Melvin, MD, MMSc

Jefferson Medical College of Thomas Jefferson University

Follow this and additional works at: https://jdc.jefferson.edu/rmfp

Part of the Rehabilitation and Therapy Commons

Let us know how access to this document benefits you

\section{Recommended Citation}

Melvin, MD, MMSc, John L., "Lessons Learned Through Leadership" (2014). Department of

Rehabilitation Medicine Faculty Papers. Paper 26.

https://jdc.jefferson.edu/rmfp/26

This Article is brought to you for free and open access by the Jefferson Digital Commons. The Jefferson Digital Commons is a service of Thomas Jefferson University's Center for Teaching and Learning (CTL). The Commons is a showcase for Jefferson books and journals, peer-reviewed scholarly publications, unique historical collections from the University archives, and teaching tools. The Jefferson Digital Commons allows researchers and interested readers anywhere in the world to learn about and keep up to date with Jefferson scholarship. This article has been accepted for inclusion in Department of Rehabilitation Medicine Faculty Papers by an authorized administrator of the Jefferson Digital Commons. For more information, please contact: JeffersonDigitalCommons@jefferson.edu. 


\title{
As submitted to:
}

\section{$P M \& R$}

\section{And later published as:}

\section{Lessons Learned Through Leadership}

\author{
John L. Melvin, MD, MMSc
}

\section{Volume 7, Issue 7, pages: 571-574, July 2014}

\section{DOI: http://dx.doi.org/10.1016/j.pmrj.2014.05.021}

\section{Introduction}

This paper identifies a number of principles I have adopted when assuming leadership roles. They evolved from experiences that suggested they would help me be more effective in these roles. I have found through using them that they are indeed helpful to me as a leader and to the organizations I lead. When comparing notes with other leaders, I find they seem to apply to others as well.

\section{Lesson 1: Allocate Sufficient Time for Leadership}

This suggestion would seem to be self-evident, yet I personally and others I have observed have underestimated the amount of time some leadership positions require. Failure to allocate enough time creates problems when leaders find they do not have the time to meet the 
requirements of their positions. With insufficient time for leadership, organizations fail to operate smoothly and to meet their goals; the leaders and others concerned for the organization develop anxiety over its ability to function properly. Often members of these organizations develop alternative patterns of decision making that bypass the unavailable leader. This leads to problems in communication and a dysfunctional organization.

Leadership requires the allocation of both planned and contingency time, i.e. time to address unexpected problems promptly. These unexpected problems can occur anytime; often at extremely inopportune times. Leaders need to allocate regular time periods to their leadership responsibilities, but have flexibility in the rest of their schedules to address these contingency problems. I suggest that leaders explicitly evaluate at intervals the amount of time they need to allocate to their leadership responsibilities. This exercise is useful in planning their schedules even if the amount of time they project is beyond that which they will be able to provide. Sources of information for these projections can be from others who have had similar positions and from the experiences of the leaders making these projections. These projections of needed time should include more than the absolute minimum, but, because of external constraints, usually do not include all of the time leaders would like to have available. There is a significant margin between the amount of time that would be ideal, and that which is satisfactory for leading organizations.

\section{Lesson 2: Leadership Requires a Different Mindset}

As clinicians, researchers and educators we strive to perform as close to perfection as possible. We evaluate ourselves and our colleagues by assessing how short we are from achieving 
perfection, even though we are usually fairly close. In this process, we often fail to acknowledge that we successfully achieved most of what we hoped to do. Examples include the reviews of our papers prior to publication or the assessment of our performance on the cases we present at grand rounds. It is important that we strive to provide the best of clinical care or the most accurate of new information to share with peers. Through our certifications, training and experiences we have demonstrated that we are able to achieve high levels of technical competence. We come to expect this level of performance from ourselves, and almost uniformly reach it unless we try to do too much with the time that is available to us. I believe this expectation exists among all high level technical professions, not just among physicians or health professionals.

Leaders, on the other hand, must become able to accept that not all of the areas for which they are responsible will achieve levels comparable to these technical standards. The resources available to organizations are finite and in my experience never enough to accomplish every aspect of their mission and goals. Some of these limitations include the time and commitment of the leader, the skills of those comprising the workforce, political realities and monetary resources. The role of leaders in these circumstances is to prioritize the allocation of resources in ways that maximize the achievement of the organizational missions and goals. Some of the organizations' activities will need to meet the high standards of technical experts, such as any clinical care they provide or the accuracy of their accounting. Other activities may be only partially accomplished or not supported at all. For example, organizations may restrict the number of sites where they provide clinical services, or they may provide only limited support to some functions, such as marketing or development. 
It often is difficult for clinicians and other technical personnel to make the transition to organizational leadership because they cannot adjust to the reality of accepting the less than perfect. Their natural compulsiveness served them well in the clinical setting, but interferes with the flexibility they need to be effective leaders. Ernie Johnson, MD, AAPM\&R past president and former Chairman of the Department of Physical Medicine and Rehabilitation at the Ohio State University told me when I was a resident that leadership was "the art of the possible". My experience is that leaders need to internalize this concept, be comfortable with what they are doing, and thus make the best decisions for their organizations.

\section{Lesson 3: Delegate to Accomplish More}

Leaders only have a finite amount of time to address all of the issues of their organizations. If they fail to delegate, they limit the scope of their organizational roles to that which they can personally accomplish. I have seen departments with limited accomplishments because their chairs have failed or been unwilling to delegate functions to their staff members. There are a number of reasons for this.

In one situation I observed, the chair of a department believed faculty members would naturally assume greater responsibility and expand their activities if the chair modeled for them the clinical activities the chair wished them to do. This approach failed because the chair did not give the faculty members explicit instructions, so they were unaware that the chair did not personally wish to provide the clinical services. They actually thought the chair was doing a very good job and did not wish to intervene. In this case, the chair failed to understand that modeling without delegation instructions was insufficient. 
I have observed other departments where the chairs performed far more clinical services than were compatible with them being able to accomplish many of their expected responsibilities. These chairs felt that they were particularly skilled at these services, and did not feel others could accomplish them at the same level. They allowed their compulsiveness to restrict their delegation, thus over working themselves, restricting the scope of their departmental activities and limiting the opportunities for their faculty members to develop additional skills.

Delegation sometimes does not occur because leaders have concerns that highly effective and accomplished junior colleagues will receive recognition that these leaders fear will over shadow their own. They may feel that these accomplished junior colleagues threaten their ability to retain their leadership positions. This fear is almost always unjustified. Leaders receive recognition for the development of their colleagues, and credit for the accomplishments these colleagues bring to their organizations.

Some leaders limit their delegation because they have concerns that the process will take more of their immediate time than they wish to provide. Delegation involves providing initial instructions, monitoring for progress and additional instructions if there are needs for improvement. However, this initial time investment almost always leads to more effective colleagues and better understanding of how to deliver those services. Delegation implies a willingness of chairs to accept some mistakes without prejudice, and using them as opportunities for all to learn. It is important, however, when delegating not to put faculty members in the position of causing harm to patients. 
The same principles apply when leading professional associations. Delegation allows leaders to expand their efforts through involving others. It also provides the opportunity to have diverse input when considering decisions, especially when organizations delegate responsibilities to task forces and committees. However, leaders continue to have the responsibility to assure that their organizations either make necessary decisions within required time frames, or provide timely reports. Their responsibility continues even if they have delegated these functions.

My experience with task forces and committees has been variable. Some get prompt responses from all of their members and compile their recommendations or reports within their assigned time targets. Others have difficulty getting responses from their members, and as a result, fail to provide their reports when they are needed. I believe in these situations that leaders must provide the expected product, utilizing the input they have available, even if it is limited or absent.

\section{Lesson 4: It is About the Organization, Not the Individual Leader}

Organizations exist to accomplish their missions or purposes. These now are usually explicitly written to guide the efforts of organizations towards focusing on the reasons for their existences. Mission statements are part of comprehensive strategic plans that can take different forms but usually include vision and values statements, goals and objectives. Although they should be revised from time to time, strategic plans provide guidance for the operations of organizations. Other than the objectives, the components of strategic plans direct the courses of organizations over several years. Leaders are responsible for guiding their 
organizations towards achieving their goals through the implementation of their strategic plans. This should provide stability and continuity to the operations of organizations.

Leaders, especially new ones, should approach making changes in organizational directions cautiously. They may have favorite projects in mind, but they should implement them only if the projects are consistent with their organizations' strategic plans, i.e. continue their previous directions. Strategic plans can be changed, but the process requires the input of all of stakeholders, so focusing on the leader's new goals is not likely to occur quickly. On the other hand, organizations should develop their strategic plans so their leaders have some flexibility in their choices of objectives. These choices are appropriate as long as they help organizations achieve their identified goals. Organizations should have enough flexibility to be able to take advantage of unique opportunities that were not available when they formulated their strategic plans.

Another reason for new leaders to implement significant changes cautiously is the danger of causing unintended consequences. These top down directives may target important objectives, but may overlook significant implications at operational levels. It is better to gain input from those at the operational levels (bottom up) before finalizing new initiatives.

\section{Lesson 5: Personnel Management is Complex and Important}

Only through experience did I realize how important the workforce of an organization is to its success, and how complex interacting with it can be. The following are some observations. 
"Interact supportively with all staff members who can influence your operations, both those internal to your organization and those external."

The support staffs of organizations control the flow of information needed for decisions. They can either facilitate or impede its processing, and often decide which depending on how they feel about the persons requesting the processing. At times approval processes includes the staffs of organizations external to your organization. Employees, both internal and external, respond positively to kindness and respect, often because they get so little of it. Too often our colleagues blame staff members for unavoidable bureaucratic rules or delays that are not their fault. This results in these staff members them being treated perfunctorily or negatively. It is wise to treat well so they will facilitate your paper work and not be motivated to keep it at the bottom of the pile.

"Assign projects and tasks when possible to those with an enthusiastic interest in them, i.e. those who will be energy sources for their completion"

The successful organization requires the successful completion of multiple projects, both operational and strategic. The likelihood of successfully completing these projects is greatly increased if their implementation is by colleagues with strong desires to see them finished. The prudent leader will select colleagues to lead the projects in which they are interested, thus having champions more likely to invest the energy necessary to succeed. Often, the availability of an enthusiastic champion will determine which among several projects a leader will decide to address.

"Devote your efforts as a leader towards making those you lead successful." 
Leaders need to define for those they lead what will constitute their success, and to work towards providing them the means to achieve these measures of success. Strategies may include career guidance, access to development courses, provision of supportive equipment and personnel, and introduction to those in the networks that facilitate advancement. The successes of a leader's staff members reflect well on the leader as well as the staff members and enhance the performance of their organization.

"Have a succession plan for all of the key positions in your organization."

The key personnel of organizations tend to undergo change with time. These changes can be from retirement, disability, promotion within the organization, reassignment and resignation. The key to avoiding organizational dysfunction after these changes is to have back up personnel available to perform the tasks of those who change status.

"Know those you work with well enough to understand them and their behaviors."

All members of an organization, including high level professionals, vary in their strengths and the ways they respond to external influences. Knowing these characteristics of their staff members can help leaders make assignments that maximize effectiveness. It also allows them to be sympathetic when staff members do not meet expectations. However, there should be clear criteria for satisfactory performance, and this sympathy should not interfere with taking appropriate corrective actions.

\section{Lesson 6: Never Take Action While Angry}


Actions under the influence of anger usually include components of aggression towards the source of the anger. During that time the desire to punish overcomes the prudent desire to do what is best for one's organization. Usually in provoking anger, the source is revealing some information that one can use to better control future interactions with that source. Once I was angry with the Vice-President of a facility responsible to do the transcription of my academic department. I found that our transcription work was being put at the bottom of the pile, and that deadlines for papers were not being met. My first inclination was to send an insulting memo (these days it would be an e-mail or text) expressing my low opinion of the VicePresident and the transcription operation. Instead, I arranged a meeting with the VicePresident, and found the President had not informed her I was paying for the transcription. She thought it was a pro bono service and placed the facility's patient records ahead of our academic work. After our meeting our transcriptions received a reasonable priority.

I have learned that if I am angry I should wait until it abates, and then decide what would be best to achieve our organizational goals. It is especially important to refrain from writing emails during even mild irritation, as it is almost impossible to keep their language from being at least subtly offensive.

\section{Conclusion}

Until I accepted this assignment to write about the lessons I have learned from leadership, I had not tried to prepare a list of them. To my surprise, the number I identified was quite large, so 
the thoughts in this paper are only selections from a much larger list. I have enjoyed the experiences that led to learning these lessons and hope to learn more in the future. 